\title{
Medievalista
}

Online

$25 \mid 2019$

Número 25

\section{Francisco José Díaz Marcilla, José Higuera Rubio (Eds), En torno a Ramón Llull. Presencia y transmisión de su obra}

Pedro Chambel

\section{CpenEdition \\ Journals}

Edição electrónica

URL: http://journals.openedition.org/medievalista/1765

DOI: 10.4000/medievalista. 1765

ISSN: 1646-740X

Editora

Instituto de Estudos Medievais - FCSH-UNL

Refêrencia eletrónica

Pedro Chambel, «Francisco José Díaz Marcilla, José Higuera Rubio (Eds), En torno a Ramón Llull. Presencia y transmisión de su obra », Medievalista [Online], 25 | 2019, posto online no dia 17 março 2019, consultado o 23 setembro 2020. URL : http://journals.openedition.org/medievalista/1765 ; DOI : https://doi.org/10.4000/medievalista.1765

Este documento foi criado de forma automática no dia 23 setembro 2020.

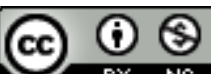

Mediavalista está licenciado com uma Licença Creative Commons - Atribuição-NãoComercial 4.0 Internacional. 


\title{
Francisco José Díaz Marcilla, José Higuera Rubio (Eds), En torno a Ramón Llull. Presencia y transmisión de su obra
}

\author{
Pedro Chambel
}

\section{REFERÊNCIA}

DÍAZ MARCILLA, Francisco José, HIGUERA RUBIO, José (eds) - En torno a Ramón Llull. Presencia y transmisión de su obra. V. N. Famalicão: Edições Húmus, 2017 (196 pp.)

\section{NOTA DO EDITOR}

Data recepção do artigo / Received for publication: 28-05-2018

En torno a Ramon Lull recolhe um conjunto de comunicações dedicadas à obra do franciscano maiorquino, apresentadas em duas reuniões organizadas pelos membros da Séccion Luliana da Societé Internationale pour l'Étude de la Phylosophie Médièvale, uma associação que surgiu com o fim de reunir num mesmo lugar os estudos dedicados a Raimundo Lulo. O volume enquandra-se nos actos que assinalaram o Any Llull, que teve lugar em 2016, para celebrar o sétimo centenário da morte do pensador e polemista medieval. Trata-se de dez estudos, precedidos por uma introdução feita pelos editores, Francisco José Díaz Marcilla e José Higuera Rubío. Nela é abordado o panorama actual dos estudos dedicados a Raimundo Lulo, e são apresentados os textos reunidos no presente volume. Estes encontram-se divididos em duas partes, formando a primeira um conjunto de quatro comunicações sob o tema Pensamento Luliano, e a segunda, seis estudos sob o título de História do Lulismo, entendendo-se por este, segundo os editores, o conjunto de obras que surgiram desde o tempo de vida do 
filósofo e que se encontram sob a influência da vida e/ou da obra deste, ou de algum dos seus herdeiros filosóficos (p. 10).

O primeiro estudo é de Antony Bordoy e surge sob o título "Ramón Llull y la discusión en torno a la existencia del averroísmo latino (siglos XIX-XX). El caso de la Declaratio Raimundi per modum dialogo edita". Analisa a tese segundo a qual a luta que Lulo moveu contra o averroísmo na Universidade de Paris teve o seu início na segunda estadia do beato maiorquino na capital francesa. Para tal, parte da Declaratio Raimudi per modum dialogi edita, o primeiro comentário que se conhece à lista de erros atribuídos a mestres e estudantes da faculdade de Artes parisienses por parte do bispo de Paris em 1277. A partir da elaboração historiográfica dos séculos XIX e XX, o autor tenta identificar os mestres assinalados como averroístas no Syllabus do bispo Tempier e no comentário de Lulo, escrito dez anos depois. A segunda comunicação, denominada "Ramon Llull y la época. Génesis histórica del pensamiento luliano", é da autoria de Gabriel Ensenyat Pujol. Tem por tópico a busca luliana do diálogo, indagando o autor a vocação de Raimundo Lulo pela conquista do "infiel", e os argumentos que empregou na prossecução deste objectivo. Com este intuito, apresenta possíveis razões que levaram o pensador franciscano a seguir um caminho próprio, tendo em vista a conversão dos muçulmanos, rejeitando assim a via característica dos dominicanos. Neste sentido, contextualiza-se a vida de Lulo e o conhecimento que tinha do mundo islâmico para explicar o percurso peculiar do Doutor Iluminado na evangelização do Islão. Em "Las subidas y bajadas de Ramon Llull - Analogías místicas y lógicas", Walter Redmond reflecte sobre as metáforas, caras ao pensador franciscano, de subida e de descida do intelecto, relacionando-as com a telogia mística de Pseudo-Dionísio. Com este fim, utiliza a obra em que Lulo as desenvolveu com maior detalhe, o Liber de ascensu et descensu intellectus.

3 A encerrar o primeiro grupo de estudos, Constantin Teleanu em "Averroes et averroista christianus: deux adversaires de Raymond Lulle à l'Université de Paris" estuda o perfil dos mestres parisiences denominados de "averroístas" pelo autor maiorquino, identificando-os como "filósofos", o que, na Faculdade de Artes de Paris, referenciava um grupo de estudiosos do filósofo árabe e de Aristóteles. O autor expressa como Lulo elabora as personificações destes mestres nos opúsculos em que com eles discute, acusando-os de seguir os "erros" do Estagirita e de Averróis.

4 No estudo que inaugura a segunda parte do livro, "El lulismo europeu medieval: una aproximación", o autor, Francisco José Díaz Marcilla, afirma que não irá fazer um estudo exaustivo, pois tal não é possível, mas uma aproximação, realizada por meio de um conjunto de propostas e ideias lançadas ao leitor, ao lulismo europeu da Idade Média. Neste sentido, apresenta um panorama introdutório ao tema, destacando a contribuição da base de dados sobre Raimundo Lulo existente na Universidade de Barcelona. É ainda efectuada uma primeira tentativa de classificação dos lulistas medievais, acompanhada de reflexões sobre o progresso dos estudos do lulismo.

5 Natália Maria Lopes Nunes é a responsável pela comunicação "O amor divino n'O livro do amigo e do amado". Esta surge na segunda seç̧ão do livro mas é apresentada pelos editores como fazendo ainda parte da primeira, onde, pela sua temática, seria lógico que aparecesse. A autora, seguindo uma metodologia comparativista, relaciona a concepção do amor divino presente na obra de Raimundo Lulo, $O$ livro do amigo e do amado, e a dos autores místicos sufis, utilizando uma recolha de textos poéticos e filosóficos árabes. Deste modo, aborda a questão da afiliação entre o pensamento de 
Lulo e o sufismo a partir d'o livro, uma obra onde o próprio autor referencia a influência do pensamento místico sufi, numa narrativa de uma das suas personagens.

6 Na terceira comunicação da parte dois, "Ramon Llull y la concepción humanista del amor (El De amore de Alain de de Varènes, un lulista "menor" del círculo lefevriano)", José Higuera Rubio estuda uma obra de um lulista francês, Alain de Varènes, que se enquadra no pensamento humanista do século XVI, tendo como referência o seu mestre Jacques Lefèvre d'Etaples, e não directamente o próprio Lulo. Deste modo, o autor demonstra a complexidade da evolução do lulismo ao longo da história do pensamento europeu. Segue-se o texto, "Una postilla su Girolamo Cardano e il lulismo", da autoria de Carla Compagno e Rafael Ramis Barceló, onde se esclarecem as relações entre a obra do beato hispânico e a de Girolamo Cardamo, sendo que no caso deste humanista, a influência do autor medievo se fez sentir na obra dedicada à alquimia. Realça-se, mais uma vez, a importância que o pensamento de Lulo adquiriu nos séculos seguintes, nomeadamente nos autores humanistas.

7 Em "Raimundo Lulo e o Livro da corte imperial: Um exemplar de literatura de polémica judaico-religiosa medieval", Alice Tavares parte das ideias e dos ideais acerca da evangelização presentes no pensamento luliano para reflectir nas soluções de conversão presentes na importante obra de polémica religiosa da literatura portuguesa medieval, o Livro da Corte Imperial. A autora centra-se no debate que no Livro opõe cristãos e judeus, para realçar o protagonismo dos objectivos lulianos, numa época de acesos debates religiosos.

8 Finalmente, em "1598: Annus mirabilis", Alessandro Tessari e Alberto Pavanato reportam-se à recuperação da obra luliana levada a cabo no século XVII, tanto a original como a que lhe foi atribuída, sendo tal fenómeno coincidente com o interesse de Filipe II e o arquitecto Juan Herrera na obra de Lullo, o que não foi suficiente para impedir a condenação de Giurdano Bruno durante o complexo período post-tridentino.

En torno a Ramon Llull é uma colectânia de comunicações que vem enriquecer o conjunto, já de si amplo, de obras dedicadas ao pensamento de Raimundo Lulo e à repercussão que o mesmo veio a adquirir nos séculos posteriores à sua morte. Deste modo, realça-se a importância do autor maiorquino, não só para a cultura e a mentalidade medievais, como para as de épocas mais tardias. 0 conjunto de textos que compõem o presente volume fazem referência não só às obras de Lulo, mas também às que lhe foram atribuídas e que influenciaram o pensamento europeu, dando um panorama introdutório à complexa questão do lulismo e da sua importância para o estudo da História das Ideias. Destaca-se ainda em En torno a Ramon Llull a introdução da responsabilidade dos editores, onde, como referimos, é abordado o estado da arte dos estudos dedicados ao autor maiorquino e ao lulismo, e são introduzidas as comunicações. O livro contém dois importantes índices, um dos manuscritos referenciados na obra, e um muito oportuno dedicado aos autores citados. Revela-se assim como uma contribuição valiosa para o estudo de um dos mais singulares autores do período medieval, incentivando a sua prossecução. De resto, a Secção Luliana da Sociedade Internacional para o Estudo da Filosofia Medieval, que se encontra na génese da colectânea de comunicações aqui analisada, tem contribuído de modo relevante para esse objectivo. Este livro, assim como as conferências que lhe deram origem, são exemplos dessa actividade. 


\section{AUTORES}

PEDRO CHAMBEL

Instituto de Estudos Medievais, Faculdade de Ciências Sociais e Humanas, Universidade Nova de Lisboa, 1069-061 Lisboa, Portugalpedrochambel@live.com.pt

https://orcid.org/0000-0002-0976-7748 